\title{
Estimation of Odds and Probability Risk Factors in Experiencing Heart Attack
}

\author{
Jackie D. Urrutia , and John Lean B. Diaz \\ Office of the Academic Head, Polytechnic University of the Philippines - Parañaque Campus \\ Col. E. L. De Leon St. Sto. Niño Parañaque City, Philippines
}

\begin{abstract}
The Heart Attack has produced an alarming rate of deaths and considered as one of the most deadly events for persons with hypertension, diabetes, with family history, a smoker and alcoholic. The study aims to produce a model using the Forward Stepwise Binary Logistic Regression Method for estimating the odds and probabilities when conceded with the given situations, and also the comparisons of the odds in which the factors are arranged by combinations of the significant variables that are included in the equation of every circumstances. Combination of covariates, gender aside, where the outcome of the study indicates that men are two times more likely to have heart attack than women. Hypertension and Diabetes, two covariates giving two of the highest odds among the factors, is 35 times more likely to trigger a heart attack than a person with none. Smoking plus the two mentioned covariates gives 114 times more. Alcohol added, has the ratio of 210 to 1 which is harshly a huge number. Summing up all the risks of the factors considered, including the family history as the last covariate, it shows the ratio 352 times that is, than a person with no complication nor any harmful vices.
\end{abstract}

\section{Introduction}

The number of cases of Heart Attack in the Philippines has a consistent escalation that makes the country $29^{\text {th }}$ on the world ranking to have the most number of deaths where 5 out of 10 Filipinos die of heart disease according to the NSO. Furthermore, World Health Organization (WHO) has said that an estimated 17 million people die of cardiovascular diseases every year. Most of these were heart attacks and strokes. Most common causes of these were other related ailments such as diabetes and hypertension that are associated with heart diseases, and harmful vices like smoking and others were recorded alcoholic.

The record data, consisting 447 number of cases from 2009-2014 in Quirino Memorial Medical Hospital, will be processed in a Logistic Regression analysis in which the intervening factors considered and their combinations are regressed against a dichotomous response variable for producing a model for the patients' chances of experiencing heart attack. Each variable and combinations of two, three, and a combination where all of the significant factors are included, will be used in the estimating odds and probabilities. Furthermore, the odds of every combination listed will be compared with the odds of a normal individual with no complications.

\subsection{Objective of the study}

The main objective of the study is to generate the odds and probabilities estimation to trigger a heart attack on patients from Quirino Memorial Medical Hospital that are having any or a combination of the intervening factors from the equations given using Binary Logistic Regression. Furthermore, it is to identify whether gender, hypertension, smoking, alcohol, diabetes or having a family history are significant and are a potent risks of having a heart attack and the odds of these factors compared with the odds of an individual with no complications.

\subsection{Scope and limitations}

The medical record from Quirino Memorial Medical Hospital of the patients, those who are at risk of experiencing heart attack, were provided by the medical management of the hospital for our study. The data gathered was limited from a total population 447 patients observed within the span of 66 months from January 2009 until June of 2014, where patients were being recorded by whether he/she(x1) has experienced(y) heart attack, if the patient is hypertensive( $\mathrm{x} 2$ ), prone to smoking(x3) or alcoholic drinks(x4), has a diabetes(x5), has a family history(x6), or no complications at all.

\subsection{Statement of the Problem}

1) What is the risk profile of the patients from the recorded data in Quirino Memorial Medical Hospital?

2) What is the binary response model that estimates the probabilities and odds for the patients who are at risk of heart attack?

3) What are the intervening factors that are significant and will be included in the model?

4) What are the odds and the probabilities of an individual, when classified with the considered significant intervening factors in the model, to trigger a heart attack? 
5) What are the odds ratios with one intervening covariate? Two or more covariates? With combinations of the covariates?

\subsection{Research paradigm}

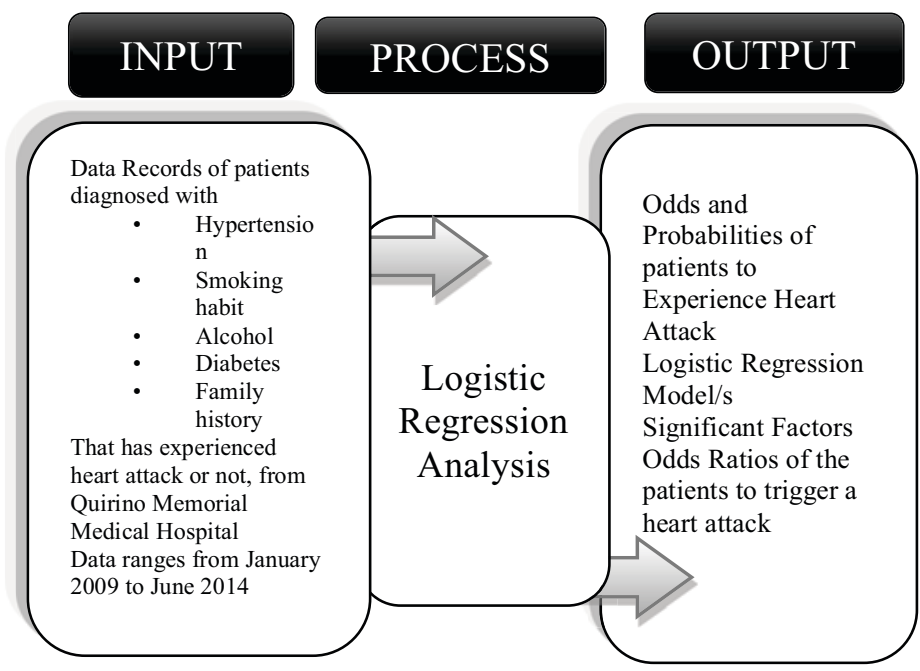

\subsection{Significance of the study}

The study may be of help in determining and estimating the odds risk of a patient to rouse a heart attack. Outcomes of the study would be a benefit to unaware individual possessing any or some of the factors, so they can make an early stage management of how to deal with their health and promote knowledgeable decisions regarding the chances they have to trigger the heart attack. These might be more possible by being more considerate of the threats of modified intervening risk factors, and might be of help to reduce the probability and the odds of the patients to experience a heart attack.

\section{Methodology}

\subsection{Population and Covariates}

The study produces a model for estimating odds and probabilities to trigger a heart attack for when a patient is either male or a female which either has been diagnosed hypertensive, a smoker, alcoholic, diabetic, and has a family history or a combination of these considered factors, by which these patients are from Quirino Memorial Medical Center.

\subsection{Logistic Regression}

The Binary-Response Logistic Regression Method is mostly used in clinical studies, epidemiology, data mining, social sciences, marketing and engineering, because it models the dependence of a binary response variable from one or more explanatory variables. The model were used in medical and social sciences because it produces and output probability that ranges between 1 and 0 which can be revised as yes or no, positive or negative, and any other dichotomous responses. This model is less restrictive than any other models when it comes to assumptions aside from the dependent variable being dichotomous or categorical, and the predictors not correlating with each other which can be detected through test of multicollinearity. Fitting it to a probability that ranges between 1 and zero, it would take the equation:

$$
\text { Probability } P\left(y \mid x_{1}, x_{2}, x_{3}, x_{4}, x_{5}, x_{6}=\frac{o d d s}{1+o d d s}=\frac{\exp \left[\beta+\beta_{1}\left(x_{1}\right)+\beta_{3}\left(x_{3}\right)+\ldots+\beta_{n}\left(x_{n}\right)\right]}{1+\exp \left[\beta+\beta_{1}\left(x_{1}\right)+\beta_{3}\left(x_{3}\right)+\ldots+\beta_{n}\left(x_{n}\right)\right]}\right.
$$

Odds are the likelihood of something happening. The chance that an event will occur divided by the probability that it will not occur. If the probability of an event occurring is $p$, the probability of the event not occurring is $(1-\mathrm{p})$.

$$
\text { odds }=\exp \left[\log \left(\frac{p}{1-p}\right)\right]=\exp \left(\beta_{0}+\beta_{1} x_{1}+\beta_{2} x_{2}+\beta_{3} x_{3}+\cdots+\beta_{n} x_{n}\right)
$$

Where $\mathrm{p}$ is the probability of interested outcome, $\beta_{0}$ is the intercept parameter, $\beta$ is a regression coefficient, and $\chi$ is a predictor. Then, it would become $e^{\beta_{1}}$ for the Odds estimated for a one unit change in $\mathrm{x}_{1}$.

Logit $=\ln ($ odds $\left.)=\ln \left(\frac{p}{1-p}\right)=\beta_{0}+\beta_{1} x_{1}+\beta_{2} x_{2}+\beta_{3} x_{3}+\cdots+\beta_{n} x_{n}\right)$

The chance that one thing will happen rather than another, the ratio of the probability of one event to that of an alternative event. Then, the corresponding odds is a value given by odds of an event $\left(\right.$ odd $\left.s_{e}\right)$ over odds alternate $\left(o d d s_{a}\right)$, which is simply can be considered as:

$$
\text { odds ratio }=\frac{o d d s_{e}}{o d d s_{a}}
$$

Also, Forward Stepwise Method is used by researchers and is a method where variables are entered in the equation one at a time to fit a model, but it differ from any other logit methods. If a variable is not significant at a specified level of significance chosen by researchers, the variable is excluded from the next model creation.

\section{Results and Discussions}

\subsection{Profile Risk}

\begin{tabular}{|c|c|c|c|c|c|}
\hline \multicolumn{2}{|c|}{ Category } & \multicolumn{4}{|c|}{ Heart Attack Experience } \\
\hline \multirow{2}{*}{$\begin{array}{c}\text { Intervening } \\
\text { Factors }\end{array}$} & \multirow{2}{*}{ Classification } & \multicolumn{2}{|c|}{$1=$ yes } & \multicolumn{2}{|c|}{$0=$ no } \\
\hline & & number & percentage & number & percentage \\
\hline \multirow{2}{*}{ Gender $\left(x_{1}\right)$} & $1=$ male & 124 & $27.74 \%$ & 40 & $8.95 \%$ \\
\hline & $0=$ female & 203 & $45.41 \%$ & 80 & $17.90 \%$ \\
\hline \multirow[b]{2}{*}{ Hypertension $\left(\mathrm{x}_{2}\right)$} & 1=hypertensive & 212 & $47.43 \%$ & 28 & $6.26 \%$ \\
\hline & $0=$ nothypertensive & 115 & $25.73 \%$ & 92 & $20.58 \%$ \\
\hline \multirow{2}{*}{ Smoking(x $\left.x_{3}\right)$} & $1=$ smoker & 180 & $40.27 \%$ & 33 & $7.38 \%$ \\
\hline & $0=$ not smoker & 147 & $32.89 \%$ & 87 & $19.46 \%$ \\
\hline \multirow[b]{2}{*}{ Alcohol $\left(x_{4}\right)$} & l=alcoholic & 189 & $42.28 \%$ & 57 & $12.75 \%$ \\
\hline & $0=$ non-alcoholic & 138 & $30.87 \%$ & 63 & $14.09 \%$ \\
\hline \multirow{2}{*}{ Diabetes( $\left(\mathbf{x}_{\mathbf{5}}\right)$} & 1=diabetic & 156 & $34.90 \%$ & 17 & $3.80 \%$ \\
\hline & $0=$ not diabetic & 171 & $38.26 \%$ & 103 & $23.04 \%$ \\
\hline \multirow{3}{*}{$\begin{array}{c}\text { Family } \\
\text { History }\left(\mathrm{x}_{6}\right) \\
\end{array}$} & $1=y e s$ & 212 & $47.43 \%$ & 58 & $12.98 \%$ \\
\hline & $0=$ no & 115 & $25.73 \%$ & 62 & $13.87 \%$ \\
\hline & & 327 & $73.15 \%$ & 120 & $26.85 \%$ \\
\hline
\end{tabular}

Table 1.

For a total of 447 patients from Quirino Memorial

Hospital, number of 327 or more than $73 \%$ of the total population has been recorded to have experienced heart attack while the rest has not experienced a heart attack. Most of them were female patients with a number of 283 , and 164 or $37 \%$ of the total number of cases were male patients. On the other hand, these patients were also classified by ailments and harmful vices namely: Hypertension, Smoking, Family History, and whether the patient is alcoholic or not. Hypertensive patients were 240 which is $53.7 \%$ of the total population of the patients whereas the rest which is 207 otherwise $46.3 \%$ were the non-hypertensive patients. Moreover, 213 patients were classified smokers for $47.7 \%$ of the entire population from the collected data, the remaining number were nonsmoker patients. Alcoholic patients have a total number 
of 246 which is $55 \%$ of the population and the nonalcoholic patients have a total of 201 patients. Nondiabetic patients have a greater in number which is 274 patients or $61.3 \%$, than the patients with diabetes for a total of 173 patients $38.7 \%$ of the entire population. Furthermore, 274 patients or $60.4 \%$ of the entire number of patients said that a member of their family has experienced having a heart attack and the rest, $39.6 \%$ of the entire number of patients or a number of 177 patients said that no member of their family that has experienced a heart attack.

\subsection{Model}

These are: male or female $\left(\mathrm{x}_{1}\right)$, hypertensive $\left(\mathrm{x}_{2}\right)$, a smoker or $\operatorname{not}\left(\mathrm{x}_{3}\right)$, the patient is alcoholic or $\operatorname{not}\left(\mathrm{x}_{4}\right)$, diabetic or not $\left(\mathrm{x}_{5}\right)$, and whether some of their family members have already experienced heart attack or has no family history of heart attack. In fitting the model into a Binary logistic regression,

$$
\begin{aligned}
& \text { Odds }=\exp \left[\log \left(\frac{p}{1-p}\right)\right]=\exp \left(\beta_{0}+\beta_{1} x_{1}+\beta_{2} x_{2}+\beta_{3} x_{3}+\beta_{4} x_{4}+\beta_{5} x_{5}+\beta_{6} x_{6}\right) \\
& \text { odds }=\exp [-1.61044338719005+0.602174493679787(\mathrm{x} 1) \\
& +1.82822458539002(\mathrm{x} 2)+1.17294305751614(\mathrm{x} 3) \\
& +0.609697762156693(\mathrm{x} 4)+1.73475041391757(\mathrm{x} 5) \\
& +0.51787722202522(\mathrm{x} 6)]
\end{aligned}
$$

then, getting the probability would be...

$P(y \mid x 1, x 2, x 3, x 4, x 5, x 6)=\frac{\text { odds }}{1+\text { odds }}$

$=\frac{\exp \left[-1.6104+0.6022\left(x_{1}\right)+1.8282\left(x_{2}\right)+1.1729\left(x_{3}\right)+0.6097\left(x_{4}\right)+1.7348\left(x_{5}\right)+0.5179\left(x_{6}\right)\right]}{1+\cos p\left[-1.6104+0.602\left(x_{1}\right)+1.828\left(x_{2}\right)+1.1729\left(x_{3}\right)+0.6097 x_{4}\right)+1.734\left(x_{5}\right)+0.517\left(x_{6}\right)}$ $=\frac{1+\exp \left[-1.6104+0.6022\left(x_{1}\right)+1.8282\left(x_{2}\right)+1.1729\left(x_{3}\right)+0.6097\left(x_{4}\right)+1.7348\left(x_{5}\right)+0.5179\left(x_{6}\right)\right]}{10}$

\subsection{Significant Factors}

Table 2. Significant Factors

\begin{tabular}{|c|c|c|}
\hline Factors & $\boldsymbol{\beta}$ & Significance \\
\hline Gender $\left(\mathbf{x}_{\mathbf{1}}\right)$ & 0.602174493679787 & 0.047 \\
\hline Hypertension $\left(\mathbf{x}_{\mathbf{2}}\right)$ & 1.82822458539002 & 0.000 \\
\hline Smoking $\left(\mathbf{x}_{\mathbf{3}}\right)$ & 1.17294305751614 & 0.000 \\
\hline Alcohol $\left(\mathbf{x}_{\mathbf{4}}\right)$ & 0.609697762156693 & 0.035 \\
\hline Diabetes( $\left.\mathbf{x}_{\mathbf{5}}\right)$ & 1.73475041391757 & 0.000 \\
\hline Family History $\left(\mathbf{x}_{\mathbf{6}}\right)$ & 0.51787722202522 & 0.044 \\
\hline Constant $(\boldsymbol{\beta})$ & -1.61044338719005 & 0.000 \\
\hline
\end{tabular}

As seen the table, all variables were statistically significant at 0.05 significance level. Gender(x1), the first variable has been considered substantial at 0.047 by which it has a lesser significance value than the 0.05 . And same, is applicable to three variables which are Hypertension(x2), Smoking(x3), and Diabetes(x5) these variables have significance probability value which nearly zero. Also, the two remaining variables, Alcohol(x4) and Family History(x6) were considered significant as well with their significance value, 0.035 and 0.044 respectively.

\subsection{Odds and Probabilities of Combined Factors}

Table 3. Odds and Probabilities of Two Factors

\begin{tabular}{|c|c|c|c|c|}
\hline \multirow{2}{*}{ Category } & \multicolumn{2}{|c|}{ Male } & \multicolumn{2}{c|}{ Female } \\
\cline { 2 - 5 } & Probabilities & Odds & Probabilities & Odds \\
\hline No complications & 0.267318768 & 0.364850027 & 0.166527064 & 0.199799006 \\
\hline Hypertensive & 0.694226935 & 2.270399238 & 0.554231126 & 1.243314998 \\
\hline Smoker & 0.541075760 & 1.179008893 & 0.392336752 & 0.645648314 \\
\hline Alcoholic & 0.401655689 & 0.671278530 & 0.268794848 & 0.367605243 \\
\hline Diabetic & 0.674032692 & 2.067792308 & 0.531036801 & 1.132363483 \\
\hline With family history & 0.379801304 & 0.612386493 & 0.251135361 & 0.33534813 \\
\hline
\end{tabular}

Using the model, the probabilities and odds are listed by the combinations of all factors that are included in the equations produced in sighting to the considered circumstances, whether the person is a male or female, hypertensive or not, a smoker or non-smoker, alcoholic or not, diabetic or not, and whether has a family history or still has none of the members of the family experienced heart attack.
Visibly in the table, gender and each of the remaining variables are entered in the equation where male has greater probabilities and odds than the female, which means the male patients has higher risks when compared to females which may perhaps be less prone to trigger a heart attack. Then, the factor that has the highest risk is the hypertension than the rest, where it has the utmost odds with 2.27 for male and 1.24 for female, and probability in which it is $69 \%$ more likely to happen for men and $55 \%$ probability for women. Diabetes has the second highest risk with 2.06 in its odds and $67 \%$ probability to trigger a heart attack for men, and 1.13 in the odds and its probability touched $53 \%$ chance to trigger a heart attack for women. Smoking also contributes a high risk to trigger a heart attack in which the results above says that smoking is the third most contributor in the odds and probability chances of male and female.

Table 4. Odds and Probabilities of Three Factors

\begin{tabular}{|c|c|c|c|c|}
\hline \multirow{2}{*}{ Category } & \multicolumn{2}{|c|}{ Male } & Female \\
\cline { 2 - 5 } & $\begin{array}{c}\text { Probabilitie } \\
\text { s }\end{array}$ & Odds & Probabilitie & Odds \\
\hline no complications & 0.26731876 & 0.36485002 & 0.16652706 & 0.19979900 \\
& 8 & 7 & 4 & 6 \\
\hline hypertension, diabetes & 0.92788904 & 12.8675174 & 0.87572242 & 7.04650403 \\
& & 1 & 6 & 4 \\
\hline smoking, hypertension & 0.88004947 & 7.33677042 & 0.80070784 & 4.01775888 \\
& 4 & 6 & 1 & 4 \\
\hline diabetes, smoking & 0.86982638 & 6.68204833 & 0.78537181 & 3.65922027 \\
\hline hypertension, family & 5 & 8 & 3 & 2 \\
\hline history & 0.79213333 & 3.81077627 & 0.67604574 & 2.08685556 \\
& 9 & & 4 & 8 \\
\hline hypertension, alcohol & 0.80684731 & 4.17725133 & 0.69582160 & 2.28754447 \\
& 4 & 1 & 6 & 4 \\
\hline diabetes, family history & 0.77632180 & 3.47070846 & 0.65524704 & 1.90062779 \\
\hline diabetes, alcohol & 5 & 8 & 6 & 3 \\
\hline smoking, family history & 0.79186092 & 3.80447985 & 0.67568348 & 2.08340753 \\
& 0.66430790 & 1.97892028 & 0.52008341 & 1.08369542 \\
\hline smoking, alcohol & 2 & 6 & 2 & 7 \\
\hline Alcohol, family history & 0.68446586 & 2.16922926 & 0.54294329 & 1.18791234 \\
& 9 & 3 & 8 & 3 \\
\hline & 0.52979119 & 1.12671474 & 0.38157502 & 0.61701101 \\
\hline
\end{tabular}

The table above has some of the odds and the probabilities from the combinations with three factors including the first variable gender, in which compared to the male or female with no complications, a person that have hypertension and diabetes has the highest odds 12.86 for men and 7.05 for women, and probability chances $93 \%$ for men and $88 \%$ for women to trigger a heart attack. The other two combinations have highest odds are not less than the 6.68 for men and 3.66 for women, and are does not fall below the percentage of $85 \%$ for men and $79 \%$ for women to trigger a heart attack. That concludes that having these circumstances, there is already a great risk to develop heart attack. The rest of the combinations did not fall below $50 \%$ of their probabilities for both men and women, and odds which fell between 5 and 1 .

Table 5. Odds and Probabilities of Four Factors

\begin{tabular}{|c|c|c|c|c|}
\hline \multirow{2}{*}{ Category } & \multicolumn{2}{|c|}{ Male } & \multicolumn{2}{c|}{ Female } \\
\cline { 2 - 5 } & Probabilities & Odds & Probabilities & Odds \\
\hline $\begin{array}{c}\text { no } \\
\text { complications }\end{array}$ & 0.267318768 & 0.364850027 & 0.166527064 & 0.199799006 \\
\hline $\begin{array}{c}\text { hypertension, } \\
\text { diabetes, } \\
\text { smoking }\end{array}$ & 0.976515481 & 41.58124247 & 0.957931405 & 22.77070109 \\
\hline $\begin{array}{c}\text { hypertension, } \\
\text { diabetes, } \\
\text { alcohol }\end{array}$ & 0.959472538 & 23.67462662 & 0.928390811 & 12.96468826 \\
\hline $\begin{array}{c}\text { hypertension, } \\
\text { diabetes, family } \\
\text { history }\end{array}$ & 0.955747561 & 21.59762441 & 0.922041157 & 11.82728126 \\
\hline $\begin{array}{c}\text { diabetes, } \\
\text { smoking, } \\
\text { alcohol }\end{array}$ & 0.924778861 & 12.29413525 & 0.870675866 & 6.732508757 \\
\hline
\end{tabular}




\begin{tabular}{|c|l|l|l|l|}
\hline $\begin{array}{c}\text { diabetes, } \\
\text { smoking, family } \\
\text { history }\end{array}$ & 0.918137173 & 11.21555664 & 0.859980415 & 6.141858025 \\
\hline $\begin{array}{c}\text { hypertension, } \\
\text { smoking, } \\
\text { alcohol }\end{array}$ & 0.9310285 & 13.49874221 & 0.88084138 & 7.392175071 \\
\hline $\begin{array}{c}\text { hypertension, } \\
\text { smoking, family } \\
\text { history }\end{array}$ & 0.924893811 & 12.31448204 & 0.87086195 & 6.743651055 \\
\hline $\begin{array}{c}\text { hypertension, } \\
\text { alcohol, family } \\
\text { history }\end{array}$ & 0.875177137 & 7.011352885 & 0.793369384 & 3.839553879 \\
\hline $\begin{array}{c}\text { diabetes, } \\
\text { alcohol, family } \\
\text { history }\end{array}$ & 0.86460268 & 6.385670557 & 0.777625476 & 3.496918006 \\
\hline $\begin{array}{c}\text { smoking, } \\
\text { alcohol, family } \\
\text { history }\end{array}$ & 0.784527638 & 3.640966426 & 0.665983534 & 1.993864379 \\
\hline
\end{tabular}

The highest odds among the men has reached 41.58, and are smokers with hypertension and diabetes, which also has the highest percentage reached $98 \%$ of the chance to trigger a heart attack. Odds and probabilities of men still show greater risks than that of the women. Most of the probabilities from the men were greater than $90 \%$. In women, have the probabilities that does not fall smaller than $60 \%$. The odds of both sections are having candidly high risks for patients, with the given circumstances, to trigger a heart attack.

Table 6. Odds and Probabilities of Five Factors

\begin{tabular}{|c|c|c|c|c|}
\hline \multirow{2}{*}{ Category } & \multicolumn{2}{|c|}{ Male } & \multicolumn{2}{c|}{ Female } \\
\cline { 2 - 5 } & Probabilities & Odds & Probabilities & Odds \\
\hline No complications & 0.267318768 & 0.364850027 & 0.166527064 & 0.199799006 \\
\hline $\begin{array}{c}\text { hypertension, } \\
\text { diabetes, smoking, } \\
\text { alcohol }\end{array}$ & 0.98709749 & 76.50429825 & 0.976687395 & 41.89524901 \\
\hline $\begin{array}{c}\text { hypertension, } \\
\text { diabetes, smoking, } \\
\text { family history }\end{array}$ & 0.985874207 & 69.79248822 & 0.97450263 & 38.21973066 \\
\hline $\begin{array}{c}\text { hypertension, } \\
\text { diabetes, alcohol, } \\
\text { family history }\end{array}$ & 0.975452252 & 39.73693429 & 0.956064662 & 21.76072188 \\
\hline $\begin{array}{c}\text { hypertension, } \\
\text { smoking, alcohol, } \\
\text { family history }\end{array}$ & 0.957729411 & 22.65711054 & 0.925414749 & 12.40747657 \\
\hline $\begin{array}{c}\text { diabetes, smoking, } \\
\text { alcohol, family } \\
\text { history }\end{array}$ & 0.95377908 & 20.6352249 & 0.918700856 & 11.30025248 \\
\hline
\end{tabular}

Five factors included in the equation, produces high probabilities for both men and women where the chances do not fall lower than $90 \%$ chance to trigger a heart attack. This indicates that having these circumstances will surely lead to a higher risks. Hypertensive male patients that are smokers, diabetic and alcoholic at the same time, has the highest risks among the listed combinations above in the table, as well as with its odds which reached 76.50 of the likelihood that a heart attack would happen and the probability that it will trigger the event is approximately $99 \%$ the chance. Comparably to the chance of a person with no complications, it shows a huge difference. The odds of the different situations given on the list also demonstrate the higher risk of these intervening factors.

Table 7. Odds and Probabilities of All Factors

\begin{tabular}{|c|c|c|c|c|}
\hline \multirow{2}{*}{ Category } & \multicolumn{2}{|c|}{ Male } & \multicolumn{2}{c|}{ Female } \\
\cline { 2 - 5 } & Probabilities & Odds & Probabilities & Odds \\
\hline No complications & 0.267318768 & 0.364850027 & 0.166527064 & 0.199799006 \\
\hline $\begin{array}{c}\text { hypertension, } \\
\text { diabetes, smoking, } \\
\text { alcohol }\end{array}$ & 0.98709749 & 76.50429825 & 0.976687395 & 41.89524901 \\
\hline $\begin{array}{c}\text { hypertension, } \\
\text { diabetes, smoking, } \\
\text { family history }\end{array}$ & 0.985874207 & 69.79248822 & 0.97450263 & 38.21973066 \\
\hline $\begin{array}{c}\text { hypertension, } \\
\text { diabetes, alcohol, } \\
\text { family history }\end{array}$ & 0.975452252 & 39.73693429 & 0.956064662 & 21.76072188 \\
\hline $\begin{array}{c}\text { hypertension, } \\
\text { smoking, alcohol, } \\
\text { family history }\end{array}$ & 0.957729411 & 22.65711054 & 0.925414749 & 12.40747657 \\
\hline $\begin{array}{c}\text { diabetes, smoking, } \\
\text { alcohol, family } \\
\text { history }\end{array}$ & 0.95377908 & 20.6352249 & 0.918700856 & 11.30025248 \\
\hline
\end{tabular}

The probability when all of the intervening factors are inserted in the equation, has reached approximately or almost a hundred percent, while the odds implies very excessive risk or likelihood for a heart attack to happen in men with 128.41 chance and 70.32 for women. Then compared with a person to be non-hypertensive, nonsmoker, non-alcoholic, non-diabetic, and has no family history, the difference is huge and is evidently perceived in the table.

\subsection{Odds Ratios of Covariate Combinations}

Table 8. Odds Ratio Male/Female

\begin{tabular}{c|c}
\hline Gender Comparison & Odds Ratio \\
male/female & 1.826085297 \\
\hline
\end{tabular}

Table above shows the comparison of the odds by gender, and the outcome indicates that men, are approximately 2 times the risk to trigger a heart attack than women. Men are usually more prone to these complications may perhaps by their harmful vices and unbalanced diet or conceivably unhealthy habits. The outcome might also imply that men may perhaps trigger a heart attack earlier than most women.

Table 9. Odds Ratio of a Covariate

\begin{tabular}{|c|c|}
\hline Complication/No complication & Odds Ratio \\
\hline Hypertension & 6.222828744 \\
\hline Smoking & 3.231489116 \\
\hline Alcohol & 1.839875235 \\
\hline Diabetes & 5.667513095 \\
\hline Family History & 1.678460866 \\
\hline
\end{tabular}

As seen in the table, having hypertension or diabetes add up to 6 times greater the risk of having a heart attack, than a person with no hypertension or diabetes. Smoking has an odds ratio of 3 is to 1 , means that a smoker is 3 times more likely to trigger a heart attack than that of a non-smoker. Likewise, being an alcoholic increases the odds of a person 2 times than nonalcoholic, the same with having family history, which if a history of an individual related to the person has already experienced a heart attack, then, he or she is also 2 times more likely to trigger a heart attack than a person with no family history.

Table 10. Odds Ratio Two Covariates
\begin{tabular}{|c|c|}
\hline Complication/No complication & Odds Ratio \\
\hline hypertension, diabetes & 35.26796339 \\
\hline smoking, hypertension & 20.10900336 \\
\hline diabetes, smoking & 18.31450688 \\
\hline hypertension, family history & 10.44477452 \\
\hline hypertension, alcohol & 11.4492285 \\
\hline diabetes, family history & 9.512698935 \\
\hline diabetes, alcohol & 10.42751699 \\
\hline smoking, family history & 5.423928018 \\
\hline smoking, alcohol & 5.945536795 \\
\hline alcohol, family history & 3.088158579 \\
\hline
\end{tabular}

The table above shows the odds ratio of the following collective groupings of the factorial combinations with two variables where the ratios can be applied to both male and female persons. Hypertensive person which is diabetic at the same time, is 35 times more likely to have a heart attack than a person that is not hypertensive nor diabetic. A hypertensive smoker is more likely having 20 times greater odds than a non-smoker and nonhypertensive individual. A diabetic smoker is 18 times more likely to have a heart attack than a person that is a non-smoker nor diabetic. The situation with the other groupings of the factors included, also had their odds compared with the odds of a person with no complications.

Table 11. Odds Ratio Three Covariates Complications/No complication - 


\begin{tabular}{|c|c|}
\hline hypertension, diabetes, smoking & 113.9680398 \\
\hline hypertension, diabetes, alcohol & 64.88865243 \\
\hline hypertension, diabetes, family history & 59.19589637 \\
\hline diabetes, smoking, alcohol & 33.69640764 \\
\hline diabetes, smoking, family history & 30.74018307 \\
\hline hypertension, smoking, alcohol & 36.99805727 \\
\hline hypertension, smoking, family history & 33.75217518 \\
\hline hypertension, alcohol, family history & 19.21708197 \\
\hline diabetes, alcohol, family history & 17.50217919 \\
\hline smoking, alcohol, family history & 9.979350836 \\
\hline
\end{tabular}

The combinations listed were the collective groupings of 3 factors. The ratios are applicable with the male and female individual. One of the comparisons that are included in the table where hypertensive smoker that has diabetes 114 times greater the risk of having a heart attack than an individual with no complications like mentioned. The same with the second highest odds ratio of a hypertensive patient with diabetes and family history, which is approximately 65 times greater the odds than a normal individual to trigger a heart attack. 59 times greater if he or she is hypertensive, diabetic and has a family history. 37 times if the person is hypertensive, smoker and alcoholic. The same applies with the rest of the combinations given.

Table 12. Odds Ratio Four Covariates

\begin{tabular}{|c|c|}
\hline Complications/No complications & Odds Ratio \\
\hline hypertension, diabetes, smoking, alcohol & 209.6869741 \\
\hline hypertension, diabetes, smoking, family history & 191.2908948 \\
\hline hypertension, diabetes, alcohol, family history & 108.9130637 \\
\hline hypertension, smoking, alcohol, family history & 62.09979123 \\
\hline diabetes, smoking, alcohol, family history & 56.55810154 \\
\hline
\end{tabular}

The listed combinations are having four intervening factors where a hypertensive diabetic person which is a smoker and an alcoholic one has 210 times greater risk than a normal individual with no complications, 191 times if the person is hypertensive diabetic smoker with family history, approximately 109 times greater risk if the person is hypertensive alcoholic with diabetes, 62 times if he or she is a hypertensive smoker and alcoholic with family history, and a diabetic smoker which is an alcoholic with family history has 57 times greater risk.

\begin{tabular}{|c|c|} 
Table 13. Odds Ratio All Five Covariates \\
\begin{tabular}{|c|c|}
\hline Complications/No complication & Odds Ratio \\
\hline $\begin{array}{c}\text { hypertension, diabetes, smoking, } \\
\text { alcohol, family history }\end{array}$ & 351.95138 \\
\hline
\end{tabular}
\end{tabular}

A person possessing all the intervening factors has the odds 352 times greater than a normal individual's chance of having a heart attack whether the person is male or a female.

\section{Conclusion and Recommendation}

Results implies that the hypertension, diabetes, smoking, alcohol, and having family history of experiencing heart attack increases the risk of developing a heart attack as indicated in the number of times the patients are compared to an individual with no complications. Additionally, gender comparison of the odds were proven that men is more likely to trigger a heart attack than women, which means men is more prone into heart diseases and may perhaps because men are inclined to having unhealthy lifestyle, unbalanced eating habits, and harmful vices that distress the body.

Investigators as well, recommend a further review of the topics discussed in basis with the study, for generating more researches about heart attack risks. Researchers suggests for patients having any or some of the intervening factors included in the study, such as hypertension and diabetes, to inquire from specialists, so that they could make more ascertained and learnt decisions regarding with these ailments and the situation they are in. As implied by the results, smoking and alcohol, as well as having a member of a family that has experienced heart attack, certainly increases the risks in an individual, then, researchers might as well recommend averting one selves from smoking and alcoholic beverages, or implement self-avoidance from these harmful habits to prevent any more complications and of course, having a healthier lifestyle to reduce the risks of triggering a heart attack whitin one's self.

References

[1] Chen, M. (2014, May 13). Hypertensive Heart Disease. Retrieved September 2015 from https://www.nlm.nih.gov/medlineplus/ency/article/000163.htm [2] Berstien, S. (2014, June 23). Alcohol and Heart Disease. Retrieved September 2015 from http://www.webmd.com/heart-disease features/alcohol-andheart-disease /

[3] Goldberg, R. (2013, August 1). Diabetes, Heart Disease and Stroke. Retrieved October 2015, from http://www.niddk.nih.gov/health-information/healthtopics/Diabetes/diabetes-heart-disease-stroke/Pages/index.aspx

[4] SoRelle, R. (n.d.). Studying Populations and Heart Disease Risk. Retrieved October 28, 2015, from http://circ.ahajournals.org/content/99/5/598.full

[5]Sindico, R. (2012, July 9). 5 out of 10 Filipinos die of heart disease - NSO. Retrieved August 29, 2015, from http://www.philstar.com/breakingnews/2012/07/09/826043/5-out-10-filipinos-die-heart-disease-nso

[6] Sandhu, R., Jimenez, M., Chiuve, S., Fitzegerald, K., Kenfield, S., Tedrow, U., \& Albert, C. (2012). Smoking, Smoking Cessation and Risk of Sudden Cardiac Death in Women. AHA Journals. Retrieved at http://circep.ahajournals.org/content/early/2012/11/16/CIRCEP.112.9752 19

[7] Klodas, E. (2014, September 10). Alcohol and Heart Disease. Article review. Retrieved at http://www.webmd.com/heart-disease/guide/heart-diseasealcohol-your-heart

[8] Woman and Heart Disease Fact Sheet. (n.d.). Retrieved August 25, 2015, from http://www.cdc.gov/dhdsp/data_statistics/fact_sheets/docs/fs_women_hea rt.pdf

[9] Cardiol, E. (2014, May 21). Diabetes, Heart Disease, and Stroke. Nih Publication No. 13-5094 August 2013. Retrieved August 26, 2015, from http://www.niddk.nih.gov/health-information/healthtopics/Diabetes/diabetes-heart-disease-stroke/Pages/index.aspx

[10]Wilkins, J., Gidding, S., Liu, K., Ning, H., Polak, J., \& Lloyd-Jones, D. (n.d.) Associations Between a Parental History of Premature Cardiovascular Disease and Coronary Calcium and Carotid Intima-Media Thickness: The Coronary Artery Risk Development In Young Adults (CARDIA) Study. Retrieved August 28, 2015, from http://www.ncbi.nlm.nih.gov/pmc/articles/PMC3779512/

[11]Dev Mukherji, Mythili, T., \& Padalia, N. (2013). A Heart Disease Prediction Model using SVM-Decision Trees-Logistic Regression (SDL) (Vol. 68). Tamil Nadu: International Journal of Computer Applications. http://research.ijcaonline.org/volume68/number16/pxc3887250.pdf

[12] Fernandes, J., Arts, J., Dimond, E., Hirshberg, S., \& Lofgren, I. (n.d.). Dietary factors are associated with coronary heart disease risk factors in college students. Retrieved September 8, 2015, from http://static1.squarespace.com/static/527944f7e4b0a241d38036af/t/529d1 c12e4b0981753a2a8a0/1386028050930/Dietary factors are associated with coronary heart disease risk factors in college students.pdf

[13]McGorrian, C., Yusuf, S., Islam, S., Jung, H., Rangarajan, S., Avezum, A., . . . Teo, K. (2011). Estimating modifiable coronary heart disease risk in multiple regions of the world: The INTERHEART Modifiable Risk Score. Retrieved September 10, 2015, from

http://www.naos.aesan.msps.es/ca/naos/ficheros/investigacion/estimating modifiable coronary heart.pdf

[14] Fukuoka, Y., Choi, J., Bender, M., \& Gonzales, P. (2015, April 20). Family history and body mass index predict perceived risks of diabetes and heart attack among community-dwelling Caucasian, Filipino, Korean, and Latino Americans-DiLH Survey. Retrieved September 10, 2015, from http://www.ncbi.nlm.nih.gov/pmc/articles/PMC4470846/

[15] Ong, W. (2011, August 30). Reducing heart disease and lifestyle diseases in the Philippines. Retrieved October 12, 2015, from http://www.philstar.com/health-and-family/721436/reducing-heartdisease-and-lifestyle-diseases-philippines

[16] Sto. Tomas, M., Baluyot, P., Delos Santos, A., Faustino, J., Licudine, E., Mendoza, E., ... Tiburcio, M. (2015). Interleukin 6 as a Biomarker of Ischemic Heart Disease (Issue 7 ed., Vol. 5, p. 4). Manila, Department of Medical Technology, University of Santo Tomas: International Journal of Scientific and Research Publications. Retrieved at http://www.ijsrp.org/research-paper-0715/ijsrp-p4316.pdf

[17] Goroscope, J., Bismonte, S., Arcilla, R., \& Gironella, G. (2014, March 6). Ordinal Logistic Regression Analyses on Anemia for Children Aged 6 
Months to 5 Years Old in the Philippines. Retrieved October 4, 2015 , from

http://www.dlsu.edu.ph/conferences/dlsu_research_congress/2014/_pdf/F NH-II-016.pdf

[18] How Does Smoking Affect the Heart and Blood Vessels? (n.d.). Retrieved September 26,2015, from

http://www.nhlbi.nih.gov/health/healthtopics/topics/smo

[19]Rundel, C. (2013, April 15). Lecture 20 - Logistic Regression Statistics 102. Retrieved August 24, 2015, from

https://stat.duke.edu/courses/Spring13/sta102.001/Lec/Lec20.pdf

[20]Noncommunicable Diseases (NCD) Country Profiles. (2014). Retrieved August 28, 2015, from http://www.who.int/nmh/countries/phl_en.pdf 